\title{
Challenges of operational river forecasting
}

Article

Published Version

Open Access

Pagano, T. C., Wood, A. W., Ramos, M.-H., Cloke, H. L., Pappenberger, F., Clark, M. P., Cranston, M., Kavetski, D., Mathevet, T., Sorooshian, S. and Verkade, J. S. (2014) Challenges of operational river forecasting. Journal of Hydrometeorology, 15 (4). pp. 1692-1707. ISSN 1525-7541 doi: https://doi.org/10.1175/JHM-D-13-0188.1 Available at https://centaur.reading.ac.uk/37907/

It is advisable to refer to the publisher's version if you intend to cite from the work. See Guidance on citing.

To link to this article DOI: http://dx.doi.org/10.1175/JHM-D-13-0188.1

Publisher: American Meteorological Society

All outputs in CentAUR are protected by Intellectual Property Rights law, including copyright law. Copyright and IPR is retained by the creators or other copyright holders. Terms and conditions for use of this material are defined in the End User Agreement.

www.reading.ac.uk/centaur

\section{CentAUR}

Central Archive at the University of Reading 
Reading's research outputs online 


\title{
${ }^{C}$ Challenges of Operational River Forecasting
}

\author{
Thomas C. Pagano, ${ }^{*}$ Andrew W. Wood,${ }^{+}$Maria-Helena Ramos, ${ }^{\#}$ Hannah L. Cloke,${ }^{@}$ \\ FlORIAN PAPPENBERGER, ${ }^{\&}$ MARTYN P. ClARK, ${ }^{+}$MiCHAEL CRANSTON, ${ }^{* *}$ DMITRI KAVETSKi,${ }^{++}$ \\ THIBAUlT MATHEVET, ${ }^{\# \#}$ SOROOSH SOROOSHIAN, ${ }^{@}$ AND JAN S. VERKADE ${ }^{\& \&}$ \\ * Bureau of Meteorology, Melbourne, Victoria, Australia \\ ${ }^{+}$National Center for Atmospheric Research, Boulder, Colorado \\ \# IRSTEA, UR HBAN, Antony, France \\ ${ }^{\circledR}$ Department of Geography and Environmental Science, and Department of Meteorology, University of Reading, \\ Reading, United Kingdom \\ ${ }^{\&}$ European Centre for Medium-Range Weather Forecasts, Reading, United Kingdom \\ ** Scottish Environment Protection Agency, Perth, United Kingdom \\ ${ }^{++}$School of Civil Environmental and Mining Engineering, University of Adelaide, Adelaide, South Australia, Australia \\ \#\# Électricité de France, Grenoble, France \\ ${ }^{\circledR}$ Henry Samueli School of Engineering, University of California, Irvine, Irvine, California \\ \&\& Deltares, and Delft University of Technology, Delft, and Ministry of Infrastructure and the Environment, Water Management \\ Centre of The Netherlands, River Forecasting Service, Lelystad, Netherlands
}

(Manuscript received 16 November 2013, in final form 22 April 2014)

\begin{abstract}
Skillful and timely streamflow forecasts are critically important to water managers and emergency protection services. To provide these forecasts, hydrologists must predict the behavior of complex coupled human-natural systems using incomplete and uncertain information and imperfect models. Moreover, operational predictions often integrate anecdotal information and unmodeled factors. Forecasting agencies face four key challenges: 1) making the most of available data, 2) making accurate predictions using models, 3 ) turning hydrometeorological forecasts into effective warnings, and 4) administering an operational service. Each challenge presents a variety of research opportunities, including the development of automated quality-control algorithms for the myriad of data used in operational streamflow forecasts, data assimilation, and ensemble forecasting techniques that allow for forecaster input, methods for using humangenerated weather forecasts quantitatively, and quantification of human interference in the hydrologic cycle. Furthermore, much can be done to improve the communication of probabilistic forecasts and to design a forecasting paradigm that effectively combines increasingly sophisticated forecasting technology with subjective forecaster expertise. These areas are described in detail to share a real-world perspective and focus for ongoing research endeavors.
\end{abstract}

\section{Introduction}

Recent water-related disasters have captured public attention and led to increased interest in hydrologic forecasting systems. Flooding was responsible for nearly half of all natural catastrophe-related losses in 2013, with floods in Europe, Asia, Canada, the United

๖ Denotes Open Access content.

Corresponding author address: Thomas C. Pagano, Bureau of Meteorology L9, 700 Collins Street, Docklands, VIC 3008, Australia. E-mail: thomas.c.pagano@gmail.com
States, and Australia causing over $\$ 20$ billion (U.S. dollars) in losses [see www.swissre.com/media/news releases/nr_20130821_sigma_natcat_estimates_H1_2013. html and Coffman (2013)]. The human toll in developing countries is staggering, with disasters routinely displacing from tens to hundreds of thousands of people; for example, nearly 2000 people were dead or missing after the Philippines typhoon of 2012, with evacuations exceeding 780000 people. Droughts can be just as damaging, with the U.S. drought of 2012 costing nearly $\$ 80$ billion (U.S. dollars).

Some of these consequences are avoidable through advance warning, emergency response, and other preparations; thus, operational river forecasters can help 


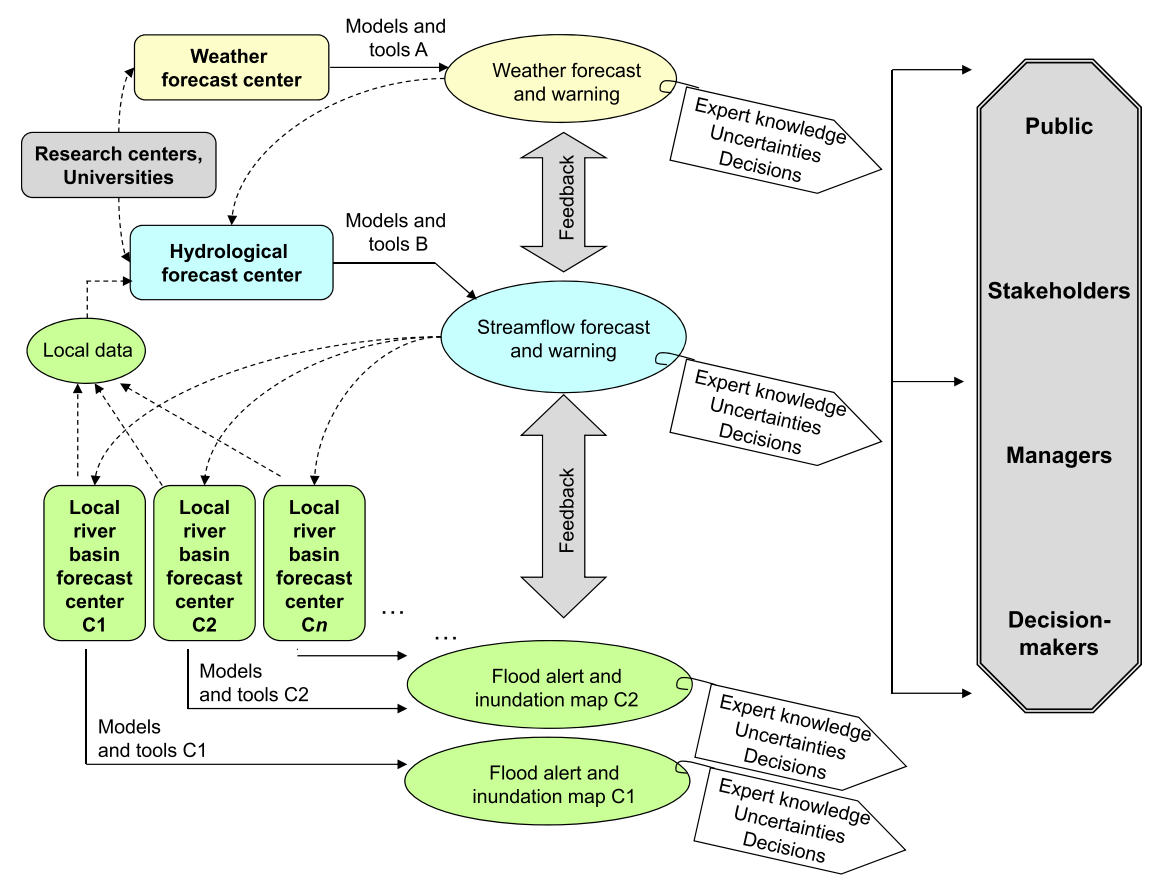

FIG. 1. Schematic view of the main interconnections in a hydrometeorological forecasting chain and its flow of uncertainties and decisions [modified from Ramos et al. (2010)].

mitigate the impacts of these disasters by providing accurate and timely information about current and anticipated hydrological conditions (Fig. 1; Carsell et al. 2004). Analyses have shown that damage reduction due to river forecast improvements can range from a few percentage points to as much as $35 \%$ of average annual flood damages (Rogers and Tsirkunov 2010). The value of the recent upgrade to the U.S. river forecasting system has been estimated at $\$ 2.1$ billion (U.S. dollars) annually (in 2013 dollars; National Hydrologic Warning Council 2002).

Hydrologists predict the behavior of rivers for applications ranging from the months-ahead estimation of water supply (particularly for droughts; Pagano et al. 2004; van Dijk et al. 2013) to hours-ahead warning of flooding (Hapuarachchi et al. 2011; Wang et al. 2009). Some forecasting centers have the capacity to switch to 24-h emergency operations in the event of a crisis (Sene 2010). During these times, forecasters maintain close contact with users and the media, updating as conditions evolve (Fig. 2). These warnings are critically important to water managers and emergency protection and response services (Hamlet et al. 2002; Hartmann et al. 2003; Pagano 2013a).

The recent availability of novel global hydrometeorological and geophysical datasets; improvements in weather, climate, and land surface models; and the applications-focused efforts of the research community mean that our current understanding of hydrologic processes is more comprehensive and nuanced than ever before, and prediction capabilities are developing at an impressive rate (NRC 2012a). Advancements in technology, communication, and computing power should position forecasting agencies to narrow the gap between state-of-the-art research and operational practices. In doing so, agencies can deliver the ever more accurate, timely, meaningful, and tailored forecasts that are sought by increasingly connected, engaged, and informed stakeholders (NRC 2013). However, forecasters must address numerous existing and emerging challenges before society can fully reap the benefits of these advancements.

Although the research literature has occasional investigations into hindcasting experiments, there is relatively little documentation of the practices and concerns of operational forecasting agencies, particularly of those in developing countries. While hydrology is a universal science and forecasters face many common challenges, particular aspects of operational forecasting depends on cultural, societal, and environmental factors. To better understand these differences, the lead author embarked on 16 months of travel through 24 developed and developing countries to visit river forecasters in their working environments. This included remaining in forecasting centers during emergency operations as flood disasters were occurring. Through discussions with 


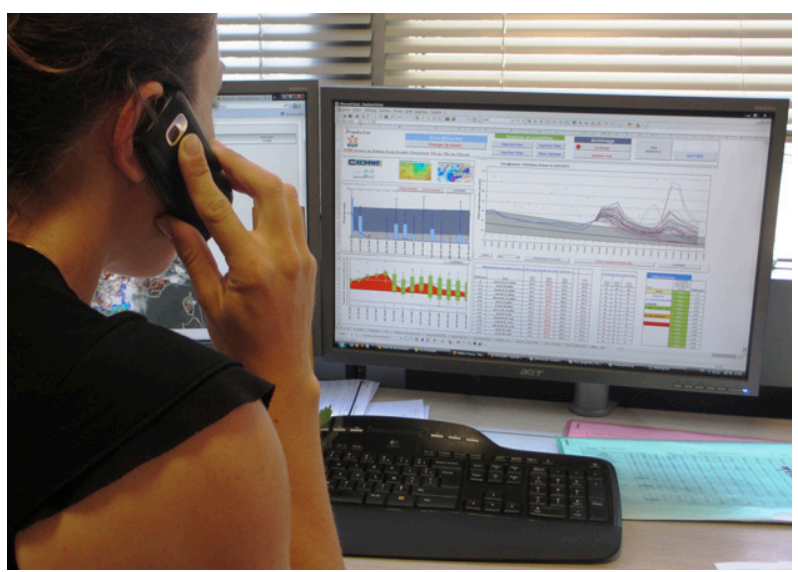

FIG. 2. Électricité de France operational river forecaster Audrey Valery consults by phone with a dam manager about floods expected on the Drac River in southeastern France. On the screen are ensemble streamflow forecasts generated by a rainfall-runoff model. Preparing and running models are only two aspects of the forecasting process. Hydrologists also coordinate with the producers of other forecasts (e.g., meteorologists), review data, interpret model output, assess forecast confidence, consider nonmodeled factors (including anecdotal information), coordinate with water managers whose actions both depend on and affect river flow, translate model output into the decision-maker's context, and respond to user requests.

forecasters, users, research scientists, and the coauthors of this paper, a unique assessment of the contemporary challenges in flood forecasting practices across the globe emerged. The main findings are reported and discussed hereafter.

This article is structured to outline four categories of challenges faced by the forecasting agencies: data, models, warnings, and the administration of an operational service (Table 1). Members of any forecasting enterprise-weather, fire or other natural hazardsface such issues, but problems that are particularly difficult in hydrology are given emphasis. This article also highlights some ongoing activities to address these challenges. It concludes with a discussion and recommendations on how to foster better linkages between the research and operations communities and reap societal benefits from emerging forecasting technologies.

\section{Challenges for river forecasters}

\section{a. Challenge 1: Making the most of data}

Forecasters commonly rely on in situ measurements of precipitation and river stage (height of the water above a fixed reference point). Stream gauges often only measure river stage, and this must be converted to flow volume using information about the riverbed cross section (which itself often changes). Where relevant, forecasters collect data about storages in reservoirs and natural lakes. Some forecasters also use snowpack, soil moisture, and/or temperature data.

Both data-rich and data-poor countries struggle with retrieving, quality controlling, infilling, formatting, archiving, and redistributing these data. For instance, in some offices of the U.S. National Weather Service (NWS), the bulk of hydrologists' work involves quality controlling hydrometeorological records (NRC 2012b) and maintaining the cyber infrastructure to process, archive, translate, and distribute the data. This task may be streamlined where data collection, management, and dissemination are standardized by one entity-that is, the U.S. Geologic Survey handles most (though not all) of the streamflow gaugings that are used in forecast operations and makes the data freely available. U.S. meteorological data collection is more diverse, a situation akin to the fragmented and often semipublic hydrologic and meteorological data collection systems found in many countries. For example, over 200 Australian water agencies have only recently adopted a common format (Walker et al. 2009) for transferring hydrological data to the Bureau of Meteorology.

Sometimes data are constrained by political and financial factors. For example, a river forecasting system for Bangladesh cannot access in situ meteorological data from the headwaters in India. Instead, data are estimated by satellites as well as global weather and basin hydrology models (Webster et al. 2010). While precipitation data are often available free of charge or widely shared on dedicated networks, streamflow and reservoir storage data are considered national assets and are either protected or sold for a fee (Viglione et al. 2010).

Operational hydrologists generally use rudimentary automated data quality-control algorithms, if they use any at all. These algorithms check for absurdities (e.g., negative precipitation), values beyond a threshold, and high rates of change. Missing values are usually ignored, set to zero, persisted from the last value, or derived using subjective expertise. In comparison, meteorologists routinely use complex algorithms to check the spatial and temporal consistency of multiple sources of data. While meteorologists assimilate tens of millions of observations per day, the typical operational hydrologist manually assimilates hundreds of observations per forecast cycle.

Automated data quality-control routines are underutilized in hydrology, and there is a critical lack of research on this issue. Some hydrometeorological situations and their representation in the monitoring data would be difficult to address with fully automated routines, 
TABLE 1. Challenges faced by operational river forecasters.

\begin{tabular}{|c|c|}
\hline Data & $\begin{array}{l}\text { 1) Hydrological data are sensitive and are not freely distributed. } \\
\text { 2) Data collection is fragmented across many agencies. } \\
\text { 3) Quality control is a time-consuming manual process. } \\
\text { 4) Automated data assimilation is underutilized. } \\
\text { 5) In situ data networks are deteriorating. }\end{array}$ \\
\hline Modeling and forecasting & $\begin{array}{l}\text { 1) Rainfall-runoff models are simple and decades old. } \\
\text { 2) Model development has not been significant. } \\
\text { 3) Skill depends strongly on adequate precipitation forecasts. } \\
\text { 4) Many important processes are not modeled or are unmodelable. }\end{array}$ \\
\hline Warning and communication & $\begin{array}{l}\text { 1) In less-developed countries, warning distribution is slow and difficult. } \\
\text { 2) Relevant warnings require local context and knowledge of community vulnerability. } \\
\text { 3) Users have diverse needs and technical sophistication. } \\
\text { 4) Users are unfamiliar with probabilistic and ensemble forecasts. }\end{array}$ \\
\hline Institutional factors & $\begin{array}{l}\text { 1) Forecasters are reluctant to take risks for fear of liability. } \\
\text { 2) Floods can be controversial because rivers are managed by people. } \\
\text { 3) Less-developed countries face brain drain. } \\
\text { 4) There is a lack of standards in training hydrologists. } \\
\text { 5) With increasing automation, the role of human forecasters is evolving. }\end{array}$ \\
\hline
\end{tabular}

however. For example, regulated rivers can have seemingly unphysical runoff time series (e.g., rapid changes from hydropower generation) and actual flash floods can appear as a spike which may be erroneously removed using primitive data quality algorithms. Similarly, ultrasonic stream gauges often register the height of barges instead of the water surface level, and these measurement errors are time consuming to remove and replace along busy waterways. Sensors in harsh environments, such as those that experience freezing, are particularly prone to malfunction. Research on the quantification of uncertainty in streamflow measurements (e.g., Hamilton and Moore 2012; Jalbert et al. 2011; Le Coz 2012; McMillan et al. 2012) has rarely been integrated into real-time forecasting applications. A similar situation exists with respect to rainfall uncertainty, which represents another major source of errors in hydrological predictions (e.g., Rossa et al. 2011; Renard et al. 2011; Zappa et al. 2011; Liechti et al. 2013). Liu et al. (2012) review the challenges and opportunities in operational hydrologic data assimilation, citing several reasons why hydrologists lag behind their meteorological counterparts. Some of these are technical (e.g., handling the lags between precipitation and streamflow), workflow based (e.g., river forecasters typically chain together several models of different processes), institutional (e.g., greater funding for meteorology), and environmental (e.g., dams interfering with natural flows). In the United States, data assimilation currently consists of manual modifications of model states and parameters by the forecasters based on their expertise. The institutional dependence on and acceptance of this practice hinders the development of automated data assimilation (Demargne et al. 2014). In European systems that have developed more recently, forecasters typically adjust model inputs or outputs, but favor automated methods for correcting model states (Weber et al. 2012).

While forecasters rely extensively on in situ measurements (Hannah et al. 2011), stream gauge networks on several continents have been on the decline over the past three decades. Large parts of northern Russia and Canada lost about 40\% of their gauges between 1986 and 1999 (Shiklomanov et al. 2002). Furthermore, most of Africa falls below the World Meteorological Organization minimum standards for stream gauge density (Vörösmarty et al. 2001). The absence of observations makes it more difficult for river forecasters to configure and calibrate models and leads to less real-time situational awareness and a diminished ability to verify forecast accuracy (Stokstad 1999). The scientific community recently completed a decade-long initiative on prediction in ungauged basins, and although initiatives such as these contributed much new understanding and many innovative techniques (Hrachowitz et al. 2013), real-time forecasting received less attention and remains a major challenge (Randrianasolo et al. 2011).

Remote sensing data sources such as satellites may be able to provide information about river width and water slope for large rivers. In forecast applications, the research community and science agencies have long pursued interests of satellite measurements of soil moisture and mountain snowpack, but without achieving substantial adoption in operational practice. Several efforts to use remotely sensed imagery in forecast operations are underway, although many challenges are formidable: for example, the often low or unknown information content of the imagery, its relatively short period of 
record, its latency and volume, and a relative lack of proven objective real-time processing techniques.

\section{RESEARCH OPPORTUNITIES}

The challenges outlined above suggest a number of questions for researchers. How can we develop comprehensive and robust automated quality-control algorithms that synthesize data from different sources to identify outliers and infill missing values? For that matter, how can objective and automated data assimilation routines take advantage of the subjective expertise and situational awareness of the forecaster? How can forecasters make quantitative use of new sources of data whose statistical properties and biases are unknown because of the lack of a long historical record? How can we make optimal use of sparse station networks, uncertain remotely sensed retrievals (radar and satellite), and numerical weather prediction (NWP) products to provide single-value or probabilistic meteorological inputs to operational hydrologic models? And, critical to the design of forecasting systems and workflows, how does one define the point at which quality-control systems are sufficiently skillful for inclusion as an automated component of operational streamflow forecasting?

\section{b. Challenge 2: Getting the numbers right}

Hydrologic models are widely used to produce streamflow forecasts. Typical forecasting procedures follow two steps: 1) the hydrologic model is run with historical in situ data up to the start of the forecast to estimate basin initial conditions such as snowpack and soil moisture, and data are used to update model states; and 2) the hydrological model is run with (an ensemble of) weather forecasts to produce (ensemble) forecasts of streamflow. The skill of streamflow forecasts depends on the capability to estimate basin initial conditions (hydrologic predictability), the skill of the meteorological forecasts (meteorological predictability), and the capabilities of the hydrologic model to simulate hydrologic processes and ultimately streamflow (Schaake et al. 2007).

Hydrologic models are therefore the lynchpin of the streamflow forecasting enterprise. As with any field, hydrologic models are articulations of the scientific community's views about how natural systems behave. However, there are stark contrasts between the current generations of operational weather prediction models (which are continually updated and run on supercomputers) and hydrologic models (which are decades old, with physics often no more than a few hundred lines of computer code).

Widely used "bucket style" rainfall-runoff models remain largely the same as when they were first developed in the 1970s (Hartmann et al. 2002). In many cases, they do not reflect our academic field understanding of the physical hydrologic processes acting in catchments (Kirchner 2006; Seibert and McDonnell 2002). Parsimonious conceptual models (e.g., Perrin et al. 2003) are popular, simple to use, and effective, despite the fact that their parameters and states are not designed to be directly compared with field measurements. Countries such as Australia still use event-based river routing models whose intellectual roots date back to the 1930s. Even basic models can perform well, however, when their parameters are tuned (calibrated) so that the simulated flows match observations over several years of historical records (Boyle et al. 2000).

While more complex hydrologic models have been developed-fully spatially distributed physically based models were already developed in the 1990s-they are computationally demanding and by some accounts do not demonstrate dramatic improvements in streamflow forecasting skill compared to simpler models (Reed et al. 2004; Smith et al. 2013). One difficulty for physically based models may be that they attempt to apply physically oriented or empirical laws relevant at fine scales (e.g., soil column infiltration dynamics measurable on the order of $0.1 \mathrm{~m}$ ) to simulate coarse catchment behavior (e.g., on the order of 1-100 km; Savenije 2009). Reconciling local-scale measurements with theories of hydrologic behavior at the catchment scale is an often cited "grand challenge" of hydrology (Beven 2007). This may partly explain why such models are rarely seen in operational hydrological forecasting (Werner et al. 2013).

In addition to the theoretical limitations, the hydrological research community has often overlooked fundamental practical requirements for robust modeling. One such example is the frequent lack of attention to numerical errors in hydrological models, which can often lead to overwhelming errors in parameter calibration and hydrological predictions (Kavetski and Clark 2011). Another historical weakness has been a reluctance to engage in systematic testing of hydrological models and their components as hypotheses of catchment systems (Clark et al. 2011).

Even with the best available models of the natural environment, however, hydrologists would still struggle to make accurate streamflow predictions at many river locations because of the effects of human interference. People interfere in the natural hydrologic cycle with dams, irrigation works, subsurface drainage, interbasin transfers, and groundwater pumping. Although there are dramatic and rapid changes when dams fail or levees break, the obstructions can be as simple as a clogged drain (Fig. 3). Many researchers study natural rivers free 


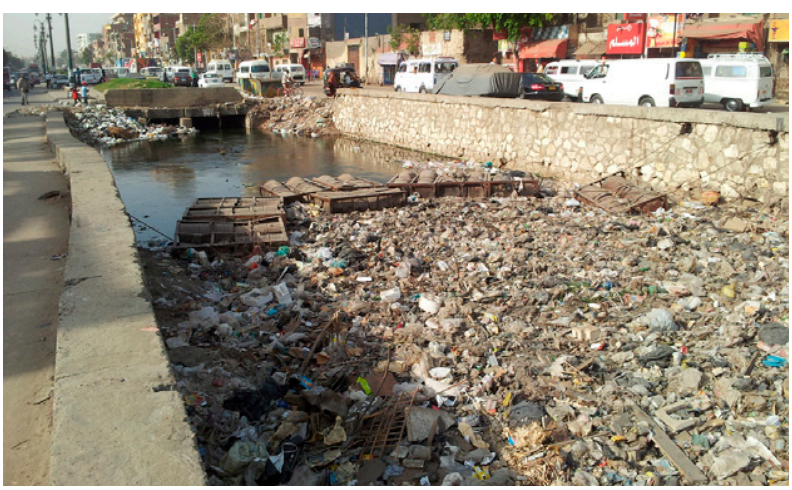

FIG. 3. The water in a channel in Giza, Egypt, is nearly completely covered by garbage and pollution. Under normal conditions, floating barrels hold back the waste, but when the flood comes, the garbage obstructs flow under bridges (in the background) and the water backs up into neighborhoods. Such microscale behavior is difficult to monitor, let alone to model or predict

from human interference, but few have attempted to understand the full complexity of evolving landscapes where such details are critically relevant. Indeed, impacts on forecasting systems have been observed; Hajtasova and Svoboda (1997) attributed the steady decline in operational forecasting skill since the 1970s in the Slovak reach of the Danube River to increased flow alteration by hydropower projects and large-scale land-use change. Conversely, when the operation of significant reservoirs is known to the forecasters, downstream conditions can be highly predictable.

The hydrologic modeling issues aside, the skill of precipitation forecasts often dictate the skill of streamflow forecasts [see Cuo et al. (2011) for a review], at least in rainfall-dominated river systems. The precipitation forecasts themselves have historically had substantial biases and low skill, particularly for extreme events, but great strides have been made in numerical weather prediction in recent years: higher-resolution and nonhydrostatic models, ensemble predictions, etc. (Pappenberger et al. 2011). Additionally, air temperature forecasts, which have much higher skill than precipitation forecasts (Clark and Hay 2004), are also useful for some hydrologic applications (e.g., snowmelt floods and river temperature forecasts).

Given the advances in NWP modeling, hydrologic forecasting would ideally utilize NWP products with high spatial resolution, long forecast lead times, reliable uncertainty estimates (e.g., calibrated ensemble predictions), and long records of retrospective forecasts consistent with the operational model. In practice, however, operational NWP usually offers one or two of these characteristics, but never all at once. In some cases, advanced NWP products may exist but are not accessible by hydrologic forecasting services. Furthermore, hydrologists are particularly interested in the location of forecasted precipitation because spatial displacement errors at catchment scales can lead to surprises and false alarms. Meteorologists typically have evaluated precipitation forecasts on synoptic scales, and local evaluations from hydrologists' perspectives are less common (Hurford et al. 2012; Shrestha et al. 2013).

Of the above data sources, hydrologists are particularly interested in retrospective weather forecasts to facilitate statistical postprocessing and downscaling. In their absence, hydrological model parameters are calibrated against historical observed weather, and little attention is paid to potential streamflow forecast biases resulting from switching to forcing the hydrological model with meteorological forecasts in real time that are likely to be inconsistent. This issue also impacts the calibration of forecasts when using postprocessing methods that depend on statistical information of past forecast performance. (e.g., Verkade et al. 2013).

In practice, operational meteorologists responsible for weather-based warnings or preparation of hydrologic forecasting model inputs use sophisticated software to merge multiple sources of NWP output with their subjective expertise. For example, the NWS Graphical Forecast Editor (GFE) system enables the use of multiple sources of NWP as a first draft of the weather forecast, and the meteorologists edit these grids using a series of "smart" tools or routines to reflect their experience and intuition (Mass 2003). The rationale behind this procedure is that these blended, subjective products allow meteorologists' collective views to correct for NWP model deficiencies, although scant research has been done on the use of GFE-style products in hydrologic forecasting. Multimodel objective blends of weather model outputs are rapidly rising in popularity (Ebert 2001) as research shows that such blends offer competitive performance to subjective forecasting, even for extreme events.

\section{RESEARCH OPPORTUNITIES}

Key questions associated with modeling and forcings employed in forecasting include the following. How can the performance of hydrologic forecasting models be quantified so as to support the production of forecasts that have low bias and are probabilistically reliable? How can we increase the agility of process-based models (e.g., find an intermediate complexity that facilitates parameter calibration where needed) and improve the relevance of hydrologic models for conditions outside the calibration period? How serious are numerical errors and how can we take advantage of well-known computational algorithms to ensure numerical robustness 
of popular legacy models? How can we best transition from calibration methodologies based on hydrograph mimicry alone (which can give the right answers for the wrong reasons) to parameter estimation methodologies that improve model representation of hydrologic processes? How can hydrologists use GFE-style weather forecasts to force hydrologic models? Can the land surface component of NWP models make hydrologic predictions that are competitive with traditional rainfallrunoff models? How can unknown human interferences in the hydrologic cycle be quantified and predicted?

\section{c. Challenge 3: Turning forecasts into effective warnings}

A recent U.S. National Research Council (NRC) report stated that " $[\mathrm{t}] \mathrm{he}$ NWS began to accept the philosophy that the perfect forecast and the most timely warning are worthless unless the individual and the community receive the information and take the necessary action to save lives and property" (NRC 2012a, p. 66). Generally, the communication and delivery of forecasts faces three challenges. Is the intended audience receiving the forecasts? Is the information being understood? Is the information being used to make the right decisions?

Some of the issues in the communication of forecasts in developing countries are structural. The lack of automated measurements, telemetry, computing resources, and communications infrastructure often limit the value of quantitative river forecasts - they would not arrive in time for users to take meaningful action. Instead, communities rely on early warning siren systems of floods already occurring upstream (Practical Action 2009), but even these approaches are fraught with technical challenges (e.g., how to power sirens when the electricity fails).

To be relevant, a river forecast is best communicated in the context of the local community. Hydrologists and emergency managers face a primary challenge of translating forecasts of, for example, flood severity at a river gauge location into flood consequences for a much broader geographic area, including ungauged reaches, associated lowlands and their developments (e.g., transportation infrastructure). Scenes of submerged automobiles on roadways provide a stark illustration of the difficulty of communicating the local relevancy of river forecasts. Such translational information is difficult to gather and maintain on a national or global scale, and therefore operational services are typically decentralized. However, such decentralization has further consequences, which are explored in the next section.

An extra dimension to this problem is the diverse array of users that each agency must serve (e.g., the public, other government agencies, and water managers), each of which has its own needs and vocabulary. Also, forecasts are repackaged and redistributed through the media, potentially distorting or oversimplifying them. River forecasters understand that predictions are uncertain, yet there is still a strong tradition of producing and communicating nonprobabilistic single-valued or categorical forecasts (NRC 2006).

There is a large range of opinions on the usefulness and comprehensibility of communications of forecast uncertainty (Bruen et al. 2010; Ramos et al. 2010). The added value of an ensemble forecast is not evident to many operational river forecasters, and its information content is contested (Demeritt et al. 2010). Ensemble forecasts are not always understood or used as much as their proponents imagine they should be, and there is considerable concern about their communication to nonexperts and user go-betweens (Pappenberger et al. 2013). Indeed, Demeritt et al. (2007) demonstrated that uncertainties can be seen as unwelcome. In contrast, some believe that "people are more capable of comprehending and using at least certain kinds of probability information than is usually noted in the information processing and subjective risk literature" (Baker 1995, p. 146). Many users do possess the technical acumen and tools to make risk-based decisions using probabilistic forecasts, particularly where the user sector contains incentives toward risk taking, such as the profit motive in the energy sector.

Some agencies struggle to define their responsibility to help users utilize forecasts. Only a few systems [e.g., the European Flood Awareness System (EFAS); Thielen et al. 2009; Bartholmes et al. 2009] have a primary mandate to provide accurate model outputs to technical experts, such as local and regional forecasters (i.e., there is no requirement to communicate forecasts to nonhydrologists such as emergency managers and the public). In contrast, for most others the challenge is greater because of the added responsibility of decision support and translation.

A common translation of an ensemble or probabilistic forecast is its distillation into an actionable planning scenario for a particular user. For instance, users may request forecasters to predict the chances of exceeding or falling below certain decision-relevant thresholds. When a hydrologist converts a probabilistic forecast into a single value, he/she is effectively determining how much risk a community should face (perhaps without the consent of the community; Pielke 1999), but typically without explaining the associated level of risk. Conversely, a forecaster may be asked to estimate the uncertainty of a single-valued forecast; this is difficult to do reliably without specific training and tools, and often impossible given the subjective 
nature of forecast production and a lack of prior forecast archives.

Uncertain forecasting alters the dynamic between forecasters and end users by giving users more ownership of-and liability for-decisions taken in the face of uncertainty. Moving from a deterministic to a probabilistic paradigm forces a redefinition of traditional professional roles and divisions of institutional responsibility for decision support and response (Ramos et al. 2013). It requires institutional and political change.

\section{RESEARCH OPPORTUNITIES}

What are the most effective methods for the communication of probabilistic and ensemble forecasts? How does the effectiveness depend on the audience? Are there efficient and scalable methods for the collection of local flood intelligence (i.e., metadata about structures and communities at risk)? Can point forecasts (e.g., at river gauges) be effectively and efficiently translated into distributed impacts?

\section{d. Challenge 4: Administering an operational service}

Amid the standard difficulties of administering service-based government organizations, hydrologists currently face three pressing issues: 1) managing institutional conservatism due to perceived liability, 2) building a base of talented employees, and 3) retaining the value of human expertise in the forecasting system.

Often forecasters maintain a low public profile, and most citizens are not generally aware that such operational services exist. Forecasting miscalculations, miscommunications, and misperceptions can have serious consequences. When the predictions work, it may be privately humbling or gratifying, but when they fail in critical situations, it is publicly humiliating. Moreover, river forecasts can be controversial and more political than weather forecasts because it is often unclear how much of any given "natural" disaster was preventable or exacerbated by human factors. If forecasters are concerned about liability, they will favor standard operating procedures over innovative but experimental techniques that are not considered "proven." This conservatism stymies progress and creates fewer opportunities to improve accuracy (Klein and Pielke 2002).

Although legal challenges against forecasters have almost never been successful (Pielke 1999), hydrologists are scrutinized when events do not go according to plan and may nonetheless have career consequences for forecasters and managers. Forecast shortcomings in 2007 led to a major institutional restructuring and changes to flood forecasting approaches in the United Kingdom (Werner et al. 2009). Brisbane, Australia, was inundated in 2011 and engineers (some of whom forecasted flows) were investigated for months to determine if the city was unnecessarily flooded after insufficient water was released in anticipation of high flows. The failure to predict a typhoon strike to Manila in 2010 led to the demotion and eventual resignation of the chief of the Philippines weather service (Cabacungan 2010). The recent conviction of scientists for misunderstandings about the risk of an Italian earthquake suggests that this issue is not just limited to floods (Anonymous 2010).

The duties of the hydrologist will determine the skills and training necessary to perform the role. The NRC has repeatedly called for requirements of hydrology degrees and/or advanced training for operational river forecasters (NRC 1996, 2006, 2012a,b). One unappreciated consequence of having nonhydrologist staff in hydrology positions is that it results in a lack of a disciplinary, interpersonal, or collegial connection of these offices with the schools, centers of research, and professional societies in hydrology and with the technical and scientific literature. Such connections would otherwise strengthen the awareness and potential transfer of new knowledge and techniques into operational settings.

Hydrologists are well served by having supplementary meteorological training given that weather observations and forecasts play such a significant role in river forecasting. The United Kingdom and other countries are innovating with programs where operational hydrologists receive meteorological training and meteorologists receive hydrological training. By the end of the cross training program, all forecasters would be qualified to perform either role or both simultaneously if required (Dale et al. 2012).

A particular challenge in countries with difficult financial conditions is "brain drain." Commonly, the best educated and most competent employees in developing countries move to work in places that provide higher pay and more resources. Australia's AUD $\$ 450$ million investment in improved water information services required the recruitment of 120 new hydrologists in 200809 , many of whom came from outside the country.

Brain drain is not always only financially motivated but can also be encouraged in the name of personal career development. In many developed countries, hydrologists are encouraged to change positions every 4-5 years to acquire diverse work experiences, at the expense of developing deeper knowledge of any one system. Changing operational interlocutors is a problem for researchers wishing to establish an ongoing relationship with a forecasting agency for the purpose of facilitating the transfer of new science into practice.

Finally, in administering an operational service, agencies must determine the role that human hydrologists should have in forecast production. The value of 
humans in weather forecasting has received much attention in recent years (Stuart et al. 2007), partly because of increasingly automated forecasting systems. Correct combined interpretation of the entire forecasting chain (i.e., initial conditions, future weather, and river response) is a crucial challenge for the hydrologist (Chardon et al. 2012; Cranston et al. 2012). Hydrologists are faced with many challenges that meteorologists (and other forecasters) do not have to contend with, such as human interference in the water cycle (e.g., reservoirs, irrigation, and flood control measures). Pagano (2013b) identified the challenges and opportunities of automation in operational river forecasting, suggesting that some tasks are more easily automated than others and that care should be taken to design automation to take advantage of human expertise.

\section{RESEARCH OPPORTUNITIES}

How important is it for operational forecasters to be modelers (and/or hydrologists), and to what extent? Which forecasting tasks can/should be automated? How can this automation be designed to create synergies between forecasters and machines? What can researchers contribute to the training programs of forecasters? How can scientists test experimental techniques under the supervision and on the terms of operational agencies, yet avoid the potential liability associated with forecasts that affect lives and property?

\section{Looking forward}

Given the challenges described above, a number of promising developments are emerging that may provide solutions. Drawing on the perspectives of operational forecasters, experiences of the authors, and trends in the research literature, we recognize several themes: the increasing recognition of forecasters' challenges as scientifically interesting, the rise of multinational forecasting systems, and new opportunities to develop better situational awareness through the use of social media. Several issues also merit open discussion: the uncertain role of the human forecaster in increasingly automated systems, the appropriate use of enhanced communications technologies to engage customers, and best approaches for fostering international collaboration. Early studies of these topics are identified, although the objective of this section is to encourage further work in these fields.

\section{a. A case for the science of hydrologic forecasting}

Two decades ago, a seminal NRC report on hydrologic science challenges and frontiers omitted discussion of forecasting on the grounds that it was applied “engineering hydrology" (NRC 1991). Hydrologic forecasting's engineering heritage has left a legacy of simplistic models and empirical tools; reductionist problem-solving approaches may have been far more pervasive in hydrology than in any other earth science (Hirschboeck 1999). These well-tested tools are effective in most circumstances but are prone to failure during extrapolation and nonstationary situations. Historically, the hydrologic research community has also had a strong interest in technology (i.e., the application of new techniques to old problems) over genuine science investigation (Klemes 1986; Nash et al. 1990).

In contrast, there have been renewed calls for the study of hydrologic forecasting science (Welles et al. 2007). Welles et al. were concerned that decisions surrounding investments to improve forecast accuracy were largely being done based on qualitative impressions from subject matter experts. Although those impressions are probably well informed, the improvements in forecast skill were not being measured, partly because some forecasts are not being archived. Welles et al. (2007) showed that U.S. operational flood forecasts had achieved no improvements in skill, despite decades of investment in science and technology. Pagano et al. (2004) showed that operational western U.S. seasonal water supply forecast skill had, at that time, fallen to levels not seen since the 1950s.

Such calls for an applied focus fit the broader trends in hydrological science. Wagener et al. (2010) called for increased cross-disciplinary focus on the study of complex real-world hydrologic systems, as opposed to pristine natural "research catchments." The follow-up to the NRC's 1991 report (NRC 2012a) listed the study of evolving systems as a major challenge; this includes understanding systems evolving because of climate change and/or human influence. The NRC also emphasized the value of interdisciplinary translational science linking researchers and decision makers. Thompson et al. (2013) and Montanari et al. (2013) reiterated these calls, emphasizing use-inspired science on "change in hydrology and society" (the theme of the International Association of Hydrological Sciences' new scientific decade of 2013-22).

The value of collaboration to forecasters is evident, but it is not a one-way trade: operational forecasters can also be a resource and source of inspiration for researchers. Forecasters often have very good mental models of how nature behaves. Forecasters routinely "crash" (i.e., encounter the limitations of) hydrologic models (Andréassian et al. 2009) and have first-hand experience battling hydrologic "monsters" (catchments with behaviors that defy expectations; Mathevet and Garçon 2010). Forecasters must deal with highly 
interdisciplinary and complex problems, including systems affected by humans. They must appreciate and anticipate the impacts of sudden and gradual changes to the watershed, including the effects of wildfire through to climate change. They can be experts in community vulnerability to hazards and must be well-versed in communication. Entraining forecasters in research also increases the chance that their real-world concerns will be addressed and the results will be adopted to improve community practice. Forecasting agencies have also expended substantial effort to collect data from myriad sources that would be useful for research.

Forecast verification is a critical component of hydrologic forecasting science, and there is a strong appetite for this information among users. Increased reporting of past forecast performance was ranked as the highest of 23 development priorities in surveys of users of a European flood forecasting system. Investment in forecast evaluation is very valuable, considering that its cost and complexity are much lower than traditional investments such as improving physical model representations (Wetterhall et al. 2013).

Hydrologic forecasting science also encompasses topics beyond the standard exercises of calibrating models and measuring performance. There has been increasing attention to the sources of uncertainty and skill in hydrologic prediction (e.g., Maurer and Lettenmaier 2003; Wood and Lettenmaier 2008; Shukla et al. 2013). This work attempts to quantify, for instance, the extent to which initial snow or soil moisture conditions may contribute to the skill of river forecasts in some regions. An open question is whether and how operational forecast skill may change as watershed hydroclimate patterns evolve because of climate change. Generalized theories of predictability of weather and climate have long existed, (Lorenz 1982) and such theories have recently emerged for soil moisture (Seneviratne and Koster 2012); research on streamflow forecast skill theory has only just begun (van Dijk et al. 2013). A further area of interest is how hydrologic prediction skill (or future changes in skill) translates into effective water management strategies, or may degrade or improve them in the future (Raff et al. 2013).

\section{b. The important role of human forecasters}

The role of the human forecaster has been part of an active and ongoing discussion in the meteorological community (Doswell 2004; Stuart et al. 2006; Sills 2009), although such conversations are nascent in hydrology. Although a "silent majority" of researchers assume that fully automated systems are better than manual ones (e.g., Parker and Fordham 1996), a few authors have forcefully contended that humans use intuition and experience to add value to the forecasts and believe that it would be a mistake to automate them out of the forecasting process (Demargne et al. 2014). In some verification experiments, human-generated flood forecasts have outperformed automated forecasts (e.g., Mathevet et al. 2012).

Various countries have widely different paradigms of automation and the relationship between hydrologists and their models. Some agencies view the hydrologist as an active model controller whereas others favor the model overseer approach (Pagano 2013b). The former makes it easier for the human to add value to the model simulation whereas the latter is more amenable to objective data assimilation, statistical postprocessing, and ensemble forecasting. Parts of the United States and the United Kingdom contract out model calibration to private consulting firms (NRC 2012c; Price et al. 2012), potentially inhibiting new employees from developing their modeling skills and innovating improvements in systems.

Blöschl (2008) provides several cases for including local information and human expertise in the flood warning process. This includes using visual inspection of landscape features to inform decisions about the processes to include in a rainfall-runoff model through to educating users about forecasts and building their trust. Pagano (2013b) explored the issue further, making recommendations on how to design river forecasting systems to make best use of subjective expertise.

\section{c. Emerging forecasting systems}

In the context of forecast automation, centralized forecasting systems having a national, transnational, and even global extent are a new development. A number of systems are operational and are seeking to evolve into mainstream sources of flood risk information. The EFAS and its global equivalent (GloFAS) are nearly completely automated and are intended to serve global disaster relief organizations and the operational agencies of countries with transboundary basins and/or relatively underdeveloped medium-range river forecasting systems (Alfieri et al. 2013). The University of Oklahoma and the National Aeronautics and Space Administration (NASA) also collaborate to provide global real-time predictions of floods and landslides based on satellite rainfall estimates (Hong et al. 2007). Converting these generalized forecasts into actionable warnings still requires local flood vulnerability information; thus, they play a complementary role to national-scale flood warning services. For instance, even though EFAS's audience is highly technically sophisticated, and the system is running for almost a decade now, some of its less technical users still struggle to 
interpret and apply its probabilistic guidance (Demeritt et al. 2013).

Given the issues of liability, some operational services sequester their forecasts (or part of their forecast information) from the public, giving access only to registered users and/or national services. Although researchers are encouraged to develop and test experimental forecasting systems as part of a demonstration project, operational agencies have concerns about real-time distribution of unofficial forecasts, especially when lives and property are at risk (Pagano et al. 2014). In contrast, meteorologists have fostered a strong sense of open competition among agencies, academic institutions, and media outlets, which has resulted in increased innovation and improved services. Indeed, the link between competition and innovation has been found in many contexts (Aghion et al. 2005).

The advent and implementation of emerging systems have partly been hindered by lack of access to real-time hydrological data. There is also not as much incentive for international collaboration in hydrology as there is in other fields (i.e., every country potentially would be interested in predictions of El Niño, but not of the flow in the Yangtze River). Although real-time data remains an issue, some hydrologists have managed to do modeling studies using unprecedented datasets from thousands of catchments in an emerging field called "large-sample hydrology" (Gupta et al. 2014).

\section{d. Building a community}

One community-oriented venue for experimentation with new forecasting systems is the Hydrologic Ensemble Prediction Experiment (HEPEX; www.hepex.org), an international initiative formed in 2004 that links researchers and forecasters. The central objective of HEPEX is to demonstrate the added value of hydrological ensemble predictions for emergency management and water resources sectors to make decisions that have important consequences for economy, public health, and safety. Working through a series of meetings, targeted workshops, and community experiments, HEPEX seeks to explore and understand operationsrelevant research topics, including six major themes: hydrological model input and preprocessing, ensemble techniques and process modeling, data assimilation, postprocessing, verification, and forecast communication and use in decision making. HEPEX also interacts with professional societies that support their own venue for discussing these topics (such as the recently formed European Geosciences Union subdivision on Hydrological Forecasting). Other recurring conferences also specialize in river forecasting topics (e.g., Western Snow Conference, American Meteorological Society, American
Geophysical Union, and HydroPredict), some of which have a regional focus (e.g., the Annual Mekong River Forum and the Conference of the Danubian Countries).

Aside from HEPEX, there are few international venues for cross collaboration among forecasting agencies. This is in part because many agencies are national in scope, and forecasting is a small subset of concerns or activities that may be raised in international memoranda of cooperation. Another factor is the tremendous specificity in forecasting system architecture, with each country developing and maintaining its own set of legacy codes, data sources, forecast user expectations, and practices. This is, however, changing somewhat with the emergence of common modular platforms, such as the Delft-Flood Early Warning System (FEWS) forecast production system (Werner et al. 2013) being used in the United States, United Kingdom, Australia, China, and dozens of other nations. Operational forecasters can benefit from international technical exchange, even if they experience different real-time contexts.

The final important community to be cared for is that of users. Forecasting agencies are faced with increased sophistication and specialization of forecast consumers and their requirements. The public is increasingly interconnected and, with enhanced communications technologies, there are great opportunities to deliver warnings through novel channels (e.g., social media). Citizens have volunteered to contribute to quantitative real-time weather observations for a number of years (Cifelli et al. 2005; Morris and Endfield 2012). The public has displayed an eagerness to feed back to forecasters information about on-the-ground conditions (e.g., uploading photographs of flooded regions to the Internet) and corporations such as Google have facilitated community mutual aid during disasters (Merchant et al. 2011; Fig. 4). How to efficiently mine (largely qualitative) social media for useful information during time-critical disasters remains an open question. Agencies are also tentatively exploring social media and mobile phones as distribution channels for geotargeted warnings (NRC 2013).

\section{Conclusions}

In this analysis, we have highlighted four major challenges for operational river forecasters: the effective use of data served by myriad sources; the generation of forecasts based on incomplete models and uncertain inputs; the conversion of numerical guidance into relevant, understandable, and actionable warnings; and the administering of robust and reliable operational services in the face of potential liability. While some of these issues cannot be addressed by the efforts of researchers 


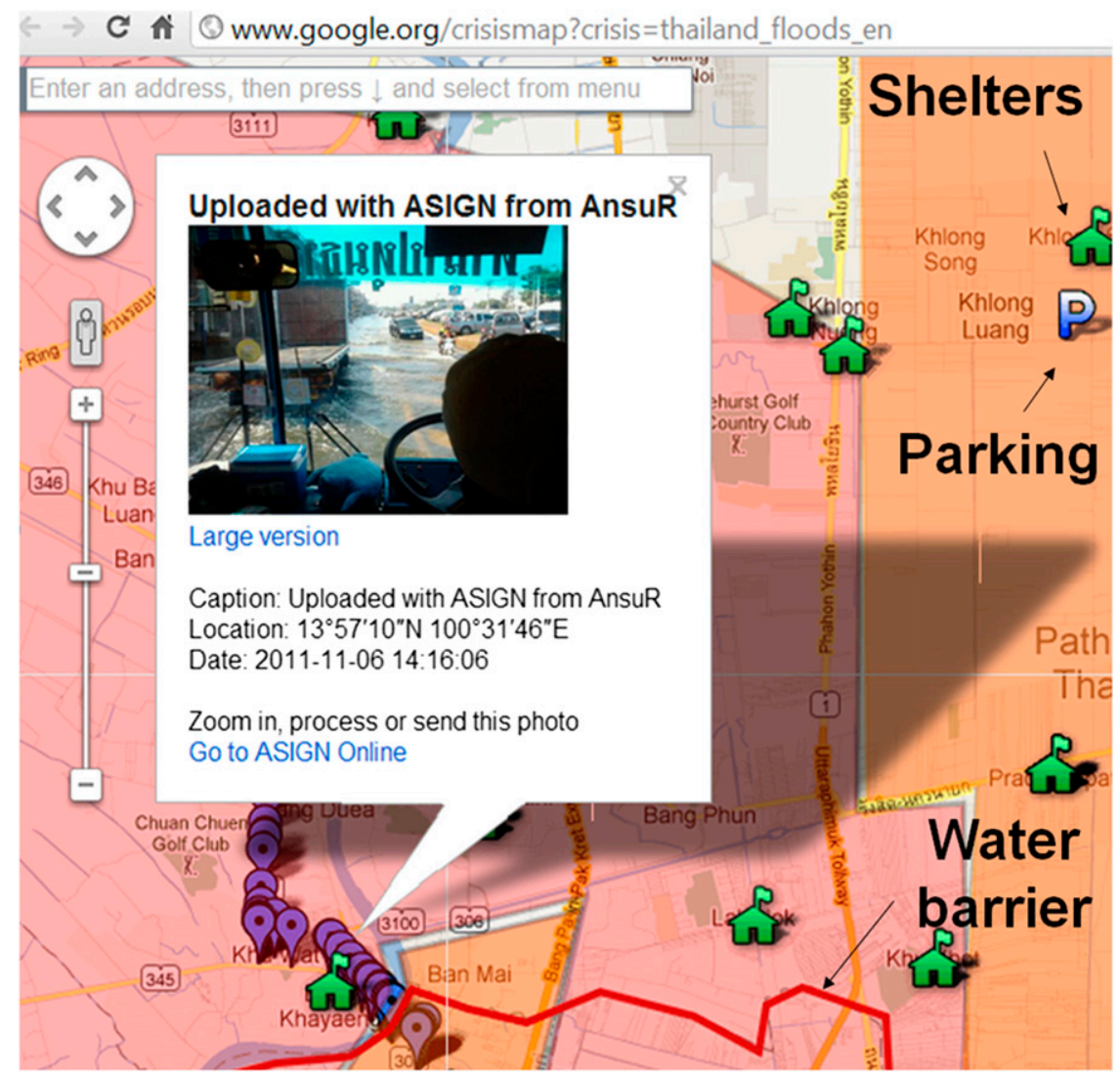

FIG. 4. In 2012 and the first half of 2013, there were special Google Crisis Response web pages (www.google.org/crisisresponse/) for floods in Russia, the Philippines, Indonesia, Canada, and India, as well as for Hurricane Sandy. The image is a screen capture of Google's web page during the Bangkok floods on 7 November 2011. Bringing together layers of data and forecasts from at least 12 government agencies, this map shows the location of shelters, parking garages, a temporary sandbag water barrier, as well as uploaded images of near-real-time conditions (in this case showing street flooding outside the barrier). The color codes are risk levels for various neighborhoods. Google also offers interactive people-finder services (i.e., "I am looking for" or "I have information about") and has responded to tornadoes, earthquakes, tsunamis, wildfires, and the Boston bombing.

alone, operational forecasting presents a sufficiently wide array of nontrivial and unanswered scientific questions that we would argue for the recognition of hydrological forecasting science as a distinct field of study.

There are many opportunities for researchers to have meaningful impacts on forecasting practices. This article identified research opportunities associated with each challenge. There needs to be work in developing automated procedures for quality control of station data and ancillary products (radar, satellite) germane for the hydrologic forecasting enterprise. There needs to be work in data assimilation and ensemble forecasting techniques that allow for forecaster input. There needs to be work in developing methods for using human-generated weather forecasts quantitatively and for quantification of human interference in the hydrologic cycle. Furthermore, much can be done to improve the communication of probabilistic forecasts and to design forecasting workflows that make best use of objective guidance and subjective expertise.

These questions are relevant to a research community increasingly interested in evolving hydrologic systems, particularly those affected by humans. Both researchers and forecasters would mutually benefit from further investigation of these issues. Efforts to bring these communities together and to engage users should be supported.

Acknowledgments. During the 16 months of travel through 24 countries, the lead author enjoyed the hospitality of innumerable national and local forecasting agencies, water users, and researchers. He was also 
supported as a visiting scientist at IRSTEA and ECMWF. These experiences are documented (http:// tompagano.blogspot.com). Special thanks are extended to local contacts William Putuhena (Research Center for Water Resources, Bandung, Indonesia), David Vallee (Northeast River Forecast Center, Taunton, Massachusetts, United States) and Mojtaba Pakparvar (Fars Research Center, Shiraz, Iran). We thank Drs. Edwin Welles and Massimiliano Zappa for their insightful reviews. Tanya Smith made valuable contributions to the editing of this manuscript.

\section{REFERENCES}

Aghion, P., N. Bloom, R. Blundell, R. Griffith, and P. Howitt, 2005: Competition and innovation: An inverted-U relationship. Quart. J. Econ., 120, 701-728, doi:10.1093/qje/120.2.701.

Alfieri, L., P. Burek, E. Dutra, B. Krzeminski, D. Muraro, J. Thielen, and F. Pappenberger, 2013: GloFAS-Global ensemble streamflow forecasting and flood early warning. Hydrol. Earth Syst. Sci., 17, 1161-1175, doi:10.5194/hess-17-1161-2013.

Andréassian, V., and Coauthors, 2009: HESS opinions: "Crash tests for a standardized evaluation of hydrological models." Hydrol. Earth Syst. Sci., 13, 1757-1764, doi:10.5194/hess-13-1757-2009.

Anonymous, 2010: AGU statement: Investigation of scientists and officials in L'Aquila, Italy, is unfounded. Eos, Trans. Amer. Geophys. Union, 91, 248, doi:10.1029/2010EO280005.

Baker, E. J., 1995: Public response to hurricane probability forecasts. Prof. Geogr., 47,137-147, doi:10.1111/j.0033-0124.1995.00137.x.

Bartholmes, J., J. Thielen, M. Ramos, and S. Gentilini, 2009: The European Flood Alert System EFAS-Part 2: Statistical skill assessment of probabilistic and deterministic operational forecasts. Hydrol. Earth Syst. Sci., 13, 141-153, doi:10.5194/ hess-13-141-2009.

Beven, K., 2007: Towards integrated environmental models of everywhere: Uncertainty, data and modelling as a learning process. Hydrol. Earth Syst. Sci., 11, 460-467, doi:10.5194/ hess-11-460-2007.

Blöschl, G., 2008: Flood warning-On the value of local information. Int. J. River Basin Manage., 6, 41-50, doi:10.1080/ 15715124.2008.9635336.

Boyle, D. P., H. V. Gupta, and S. Sorooshian, 2000: Toward improved calibration of hydrologic models: Combining the strengths of manual and automatic methods. Water Resour. Res., 36, 3663-3674, doi:10.1029/2000WR900207.

Bruen, M., P. Krahe, M. Zappa, J. Olsson, B. Vehvilainen, K. Kok, and K. Daamen, 2010: Visualizing flood forecasting uncertainty: some current European EPS platforms-COST731 working group 3. Atmos. Sci. Lett., 11, 92-99, doi:10.1002/ asl.258.

Cabacungan, G. C., Jr., 2010: Move on, science chief urges exPAGASA head. Philippine Daily Inquirer, 3 September. [Available online at http://article.wn.com/view/2010/09/03/ Move_on_science_chief_urges_exPAGASA_head/]

Carsell, K. M., N. D. Pingel, and D. T. Ford, 2004: Quantifying the benefit of a flood warning system. Nat. Hazards Rev., 5, 131140, doi:10.1061/(ASCE)1527-6988(2004)5:3(131).

Chardon, J., T. Mathevet, M. Le Lay, and J. Gailhard, 2012: Comparison of ensemble post-processing approaches, based on empirical and dynamical error modelisation of rainfall-runoff model forecasts. Geophysical Research Abstracts, Vol. 14, Abstract EGU2012-2808. [Available online at http://meetingorganizer.copernicus.org/EGU2012/ EGU2012-2808.pdf.]

Cifelli, R., N. Doesken, P. Kennedy, L. D. Carey, S. A. Rutledge, C. Gimmestad, and T. Depue, 2005: The Community Collaborative Rain, Hail, and Snow Network: Informal education for scientists and citizens. Bull. Amer. Meteor. Soc., 86,1069-1077, doi:10.1175/BAMS-86-8-1069.

Clark, M. P., and L. E. Hay, 2004: Use of medium-range numerical weather prediction model output to produce forecasts of streamflow. J. Hydrometeor., 5, 15-32, doi:10.1175/ 1525-7541(2004)005<0015:UOMNWP>2.0.CO;2.

- D. Kavetski, and F. Fenicia, 2011: Pursuing the method of multiple working hypotheses for hydrological modeling. Water Resour. Res., 47, W09301, doi:10.1029/2010WR009827.

Coffman, K., 2013: Property losses from Colorado flood projected at about $\$ 2$ billion. Reuters, 19 September. [Available online at www.reuters.com/article/2013/09/19/ us-usa-colorado-flooding-idUSBRE98H1BA20130919.]

Cranston, M., and Coauthors, 2012: Countrywide flood forecasting in Scotland: Challenges for hydrometeorological model uncertainty and prediction. IAHS Publ., 351, 538-543.

Cuo, L., T. C. Pagano, and Q. J. Wang, 2011: A review of quantitative precipitation forecasts and their use in short- to medium-range streamflow forecasting. J. Hydrometeor., 12, 713-728, doi:10.1175/2011JHM1347.1.

Dale, M., P. Davies, and T. Harrison, 2012: Review of recent advances in UK operational hydrometeorology. Proc. Inst. Civ. Eng. Water Manage., 165, 55-64, doi:10.1680/wama.2012.165.2.55.

Demargne, J., and Coauthors, 2014: The science of NOAA's Operational Hydrologic Ensemble Forecast Service. Bull. Amer. Meteor. Soc., 95, 79-98, doi:10.1175/BAMS-D-12-00081.1.

Demeritt, D., H. Cloke, F. Pappenberger, J. Thielen, J. Bartholmes, and M. H. Ramos, 2007: Ensemble predictions and perceptions of risk, uncertainty, and error in flood forecasting. Environ. Hazards, 7, 115-127, doi:10.1016/j.envhaz.2007.05.001.

— S. Nobert, H. L. Cloke, and F. Pappenberger, 2010: Challenges in communicating and using ensembles in operational flood forecasting. Meteor. Appl., 17, 209-222, doi:10.1002/met.194.

,,--- , and,- 2013 : The European Flood Alert System and the communication, perception, and use of ensemble predictions for operational flood risk management. Hydrol. Processes, 27, 147-157, doi:10.1002/hyp.9419.

Doswell, C. A., III, 2004: Weather forecasting by humansHeuristics and decision making. Wea. Forecasting, 19, 11151126, doi:10.1175/WAF-821.1.

Ebert, E. E., 2001: Ability of a poor man's ensemble to predict the probability and distribution of precipitation. Mon. Wea. Rev., 129, 2461-2480, doi:10.1175/1520-0493(2001)129<2461: AOAPMS $>2.0 . \mathrm{CO} ; 2$.

Gupta, H., C. Perrin, G. Blöschl, A. Montanari, R. Kumar, M. Clark, and V. Andréassian, 2014: Large-sample hydrology: A need to balance depth with breadth. Hydrol. Earth Syst. Sci., 18, 463-477, doi:10.5194/hess-18-463-2014.

Hajtasova, K., and A. Svoboda, 1997: Forecasts on the Slovak reach of the River Danube-Problems and methods. IAHS Publ., 239, 237-244.

Hamilton, A., and R. Moore, 2012: Quantifying uncertainty in streamflow records. Can. Water Resour. J., 37, 3-21, doi:10.4296/ cwrj3701865.

Hamlet, A. F., D. Huppert, and D. P. Lettenmaier, 2002: Economic value of long-lead streamflow forecasts for Columbia River 
hydropower. J. Water Resour. Plann. Manage., 128, 91-101, doi:10.1061/(ASCE)0733-9496(2002)128:2(91).

Hannah, D. M., S. Demuth, H. A. van Lanen, U. Looser, C. Prudhomme, G. Rees, K. Stahl, and L. M. Tallaksen, 2011: Large-scale river flow archives: Importance, current status and future needs. Hydrol. Processes, 25, 1191-1200, doi:10.1002/ hyp.7794.

Hapuarachchi, H. A. P., Q. J. Wang, and T. C. Pagano, 2011: A review of advances in flash flood forecasting. Hydrol. Processes, 25, 2771-2784, doi:10.1002/hyp.8040.

Hartmann, H. C., T. Pagano, R. Bales, and S. Sorooshian, 2002: Weather, climate, and hydrologic forecasting for the US Southwest: A survey. Climate Res., 21, 239-258, doi:10.3354/ cr021239.

_ - A. Bradley, and A. F. Hamlet, 2003: Advanced hydrologic predictions for improving water management. Water: Science, Policy, and Management, R. Lawford et al., Eds., Amer. Geophys. Union, 285-307, doi:10.1029/016WM17.

Hirschboeck, K. K., 1999: A room with a view: Some geographic perspectives on dilettantism, cross-training, and scale in hydrology. Ann. Assoc. Amer. Geogr., 89, 696-706, doi:10.1111/ 0004-5608.00170.

Hong, Y., R. F. Adler, F. Hossain, S. Curtis, and G. J. Huffman, 2007: A first approach to global runoff simulation using satellite rainfall estimation. Water Resour. Res., 43, W08502, doi:10.1029/2006WR005739.

Hrachowitz, M., and Coauthors, 2013: A decade of Predictions in Ungauged Basins (PUB)—A review. Hydrol. Sci. J., 58, 1198 1255, doi:10.1080/02626667.2013.803183.

Hurford, A. P., S. J. Priest, D. J. Parker, and D. M. Lumbroso, 2012: The effectiveness of extreme rainfall alerts in predicting surface water flooding in England and Wales. Int. J. Climatol., 32, 1768-1774, doi:10.1002/joc.2391.

Jalbert, J., T. Mathevet, and A.-C. Favre, 2011: Temporal uncertainty estimation of discharges from rating curves using a variographic analysis. J. Hydrol., 397, 83-92, doi:10.1016/ j.jhydrol.2010.11.031.

Kavetski, D., and M. P. Clark, 2011: Numerical troubles in conceptual hydrology: Approximations, absurdities and impact on hypothesis testing. Hydrol. Processes, 25, 661-670, doi:10.1002/ hyp.7899.

Kirchner, J. W., 2006: Getting the right answers for the right reasons: Linking measurements, analyses, and models to advance the science of hydrology. Water Resour. Res., 42, W03S04, doi:10.1029/2005WR004362.

Klein, R., and R. A. Pielke Jr., 2002: Bad weather? Then sue the weatherman! Part I: Legal liability for public sector forecasts. Bull. Amer. Meteor. Soc., 83, 1791-1799, doi:10.1175/ BAMS-83-12-1791.

Klemes, V., 1986: Dilettantism in hydrology: Transition or destiny? Water Resour. Res., 22, 177S-188S, doi:10.1029/ WR022i09Sp0177S.

Le Coz, J., 2012: A literature review of methods for estimating the uncertainty associated with stage-discharge relations. WMO Rep. PO6a, 21 pp. [Available online at www.wmo.int/pages/prog/hwrp/Flow/flow_tech/documents/ WMO_PO6a_RC_uncertainty.pdf.]

Liechti, K., M. Zappa, F. Fundel, and U. Germann, 2013: Probabilistic evaluation of ensemble discharge nowcasts in two nested Alpine basins prone to flash floods. Hydrol. Processes, 27, 5-17, doi:10.1002/hyp.9458.

Liu, Y., and Coauthors, 2012: Advancing data assimilation in operational hydrologic forecasting: Progresses, challenges, and emerging opportunities. Hydrol. Earth Syst. Sci., 16, 38633887, doi:10.5194/hess-16-3863-2012.

Lorenz, E., 1982: Atmospheric predictability experiments with a large numerical model. Tellus, 34A, 505-513, doi:10.1111/ j.2153-3490.1982.tb01839.x.

Mass, C. F., 2003: IFPS and the future of the National Weather Service. Wea. Forecasting, 18, 75-79, doi:10.1175/ 1520-0434(2003)018<0075:IATFOT $>2.0$. CO;2.

Mathevet, T., and R. Garçon, 2010: Tall tales from the hydrological crypt: Are models monsters? Hydrol. Sci. J., 55, 857-871, doi:10.1080/02626667.2010.503934.

, L. Moulin, J. Gailhard, R. Garçon, P. Bernard, M. Le Lay, I. Zalachori, and J. Chardon, 2012: A one year experience of an operational streamflow ensemble forecasting chain taking into account human expertise. Geophysical Research Abstracts, Vol. 14, Abstract EGU2012-11909. [Available online at http://meetingorganizer.copernicus.org/EGU2012/ EGU2012-11909.pdf.]

Maurer, E. P., and D. P. Lettenmaier, 2003: Predictability of seasonal runoff in the Mississippi River basin. J. Geophys. Res., 108, 8607, doi:10.1029/2002JD002555.

McMillan, H., T. Krueger, and J. Freer, 2012: Benchmarking observational uncertainties for hydrology: Rainfall, river discharge and water quality. Hydrol. Processes, 26, 4078-4111, doi:10.1002/hyp.9384.

Merchant, R. M., S. Elmer, and N. Lurie, 2011: Integrating social media into emergency-preparedness efforts. N. Engl. J. Med., 365, 289-291, doi:10.1056/NEJMp1103591.

Montanari, A., and Coauthors, 2013: "Panta Rhei-Everything Flows": Change in hydrology and society-The IAHS Scientific Decade 2013-2022. Hydrol. Sci. J., 58, 1256-1275, doi:10.1080/02626667.2013.809088.

Morris, C., and G. Endfield, 2012: Exploring contemporary amateur meteorology through an historical lens. Weather, 67, 4-8, doi:10.1002/wea. 800

Nash, J., P. Eagleson, J. Philip, W. Van der Molen, and V. Klemeš, 1990: The education of hydrologists (report of an IAHS/ UNESCO panel on hydrological education). Hydrol. Sci. J., 35, 597-607, doi:10.1080/02626669009492466.

National Hydrologic Warning Council, 2002: Use and benefits of the National Weather Service river and flood forecasts. NWS Rep., 33 pp. [Available online at www.nws.noaa.gov/oh/ahps/ AHPS\%20Benefits.pdf.]

NRC, 1991: Opportunities in the Hydrologic Sciences. National Academies Press, 16 pp.

- 1996: Assessment of Hydrologic and Hydrometeorological Operations and Services. National Academies Press, $62 \mathrm{pp}$.

— 2006: Toward a New Advanced Hydrologic Prediction Service (AHPS). National Academies Press, 84 pp.

, 2012a: The National Weather Service Modernization and Associated Restructuring: A Retrospective Assessment. National Academies Press, $140 \mathrm{pp}$.

- 2012b: Weather Services for the Nation: Becoming Second to None. National Academies Press, $74 \mathrm{pp}$.

- 2012c: Challenges and Opportunities in the Hydrologic Sciences. National Academies Press, 200 pp.

2013: Public Response to Alerts and Warnings Using Social Media: Report of a Workshop on Current Knowledge and Research Gaps. National Academies Press, 78 pp.

Pagano, T. C., 2013a: Evaluation of Mekong River Commission operational flood forecasts, 2000-2012. Hydrol. Earth Syst. Sci. Discuss., 10, 14 433-14 461, doi:10.5194/hessd-10-14433-2013. 
_ 2013b: International review of the role of automation in river forecasting systems. Tech. Rep., Bureau of Meteorology, Melbourne, VIC, Australia, 69 pp.

- D. Garen, and S. Sorooshian, 2004: Evaluation of official western U.S. seasonal water supply outlooks, 1922-2002. J. Hydrometeor., 5, 896-909, doi:10.1175/1525-7541(2004)005<0896: EOOWUS $>2.0 . \mathrm{CO} ; 2$.

— water supply forecasting: A tradition evolves. EOS Trans. Amer. Geophys. Union, 95, 28-29, doi:10.1002/2014EO030007.

Pappenberger, F., J. Thielen, and M. Del Medico, 2011: The impact of weather forecast improvements on large scale hydrology: Analysing a decade of forecasts of the European Flood Alert System. Hydrol. Processes, 25, 1091-1113, doi:10.1002/ hyp.7772.

— E. Stephens, J. Thielen, P. Salamon, D. Demeritt, S. J. Andel, F. Wetterhall, and L. Alfieri, 2013: Visualizing probabilistic flood forecast information: Expert preferences and perceptions of best practice in uncertainty communication. Hydrol. Processes, 27, 132-146, doi:10.1002/hyp.9253.

Parker, D., and M. Fordham, 1996: An evaluation of flood forecasting, warning and response systems in the European Union. Water Resour. Manage., 10, 279-302, doi:10.1007/BF00508897.

Perrin, C., C. Michel, and V. Andréassian, 2003: Improvement of a parsimonious model for streamflow simulation. J. Hydrol., 279, 275-289, doi:10.1016/S0022-1694(03)00225-7.

Pielke, R. A., Jr., 1999: Who decides? Forecasts and responsibilities in the 1997 Red River flood. Appl. Behav. Sci. Rev., 7, 83-101, doi:10.1016/S1068-8595(00)80012-4.

Practical Action, 2009: Early warning saving lives. Tech. Rep., 32 pp. [Available online at http://practicalaction.org/docs/ region_nepal/early-warning-saving-lives.pdf.]

Price, D., and Coauthors, 2012: Operational use of a grid-based model for flood forecasting. Proc. Inst. Civ. Eng. Water Manage., 165, 65-77, doi:10.1680/wama.2012.165.2.65.

Raff, D., L. Brekke, K. Werner, A. Wood, and K. White, 2013: Shortterm water management decisions: User needs for improved climate, weather, and hydrologic information. Tech. Rep. CWTS 2013-1, U.S. Bureau of Reclamation, 233 pp. [Available online at www.ccawwg.us/docs/Short-Term_Water_Management_ Decisions_Final_3_Jan_2013.pdf.]

Ramos, M. H., T. Mathevet, J. Thielen, and F. Pappenberger, 2010: Communicating uncertainty in hydro-meteorological forecasts: Mission impossible? Meteor. Appl., 17, 223-235, doi:10.1002/met.202.

_ - S. V. Andel, and F. Pappenberger, 2013: Do probabilistic forecasts lead to better decisions? Hydrol. Earth Syst. Sci., 17, 2219-2232, doi:10.5194/hess-17-2219-2013.

Randrianasolo, A., M. Ramos, and V. Andréassian, 2011: Hydrological ensemble forecasting at ungauged basins: Using neighbour catchments for model setup and updating. $A d v$. Geosci., 29, 1-11, doi:10.5194/adgeo-29-1-2011.

Reed, S., and Coauthors, 2004: Overall distributed model intercomparison project results. J. Hydrol., 298, 27-60, doi:10.1016/j.jhydrol.2004.03.031.

Renard, B., D. Kavetski, E. Leblois, M. Thyer, G. Kuczera and S. W. Franks, 2011: Toward a reliable decomposition of predictive uncertainty in hydrological modeling: Characterizing rainfall errors using conditional simulation. Water Resour. Res., 47, W11516, doi:10.1029/2011WR010643.

Rogers, D., and V. Tsirkunov, 2010: Costs and benefits of early warning systems. Global Assessment Rep. 2011, United Nations International Strategy for Disaster Reduction, 16 pp. [Available online at http://documents.worldbank.org/curated/en/2010/01/ 16292106/global-assessment-report-disaster-risk-reductioncosts-benefits-early-warning-systems.]

Rossa, A., K. Liechti, M. Zappa, M. Bruen, U. Germann, G. Haase, C. Keil, and P. Krahe, 2011: The COST 731 action: A review on uncertainty propagation in advanced hydro-meteorological forecast systems. Atmos. Res., 100, 150-167, doi:10.1016/ j.atmosres.2010.11.016.

Savenije, G., 2009: HESS opinions: "The art of hydrology." Hydrol. Earth Syst. Sci., 13, 157-161, doi:10.5194/hess-13-157-2009.

Schaake, J. C., T. M. Hamill, R. Buizza, and M. Clark, 2007: HEPEX: The Hydrological Ensemble Prediction Experiment. Bull. Amer. Meteor. Soc., 88, 1541-1547, doi:10.1175/ BAMS-88-10-1541.

Seibert, J., and J. J. McDonnell, 2002: On the dialog between experimentalist and modeler in catchment hydrology: Use of soft data for multicriteria model calibration. Water Resour. Res., 38, 1241-1254, doi:10.1029/2001WR000978.

Sene, K., 2010: Hydrometeorology: Forecasting and Applications. Springer, $356 \mathrm{pp}$.

Seneviratne, S. I., and R. D. Koster, 2012: A revised framework for analyzing soil moisture memory in climate data: Derivation and interpretation. J. Hydrometeor., 13, 404-412, doi:10.1175/ JHM-D-11-044.1.

Shiklomanov, A., R. Lammers, and C. J. Vörösmarty, 2002: Widespread decline in hydrological monitoring threatens pan-Arctic research. Eos, Trans. Amer. Geophys. Union, 83, 13-17, doi:10.1029/2002EO000007.

Shrestha, D. L., D. E. Robertson, Q. J. Wang, T. C. Pagano, and H. A. P. Hapuarachchi, 2013: Evaluation of numerical weather prediction model precipitation forecasts for short-term streamflow forecasting purpose. Hydrol. Earth Syst. Sci., 17, 1913-1931, doi:10.5194/hess-17-1913-2013.

Shukla, S., J. Sheffield, E. F. Wood, and D. P. Lettenmaier, 2013: On the sources of global land surface hydrologic predictability. Hydrol. Earth Syst. Sci., 17, 2781-2796, doi:10.5194/ hess-17-2781-2013.

Sills, D. M. L., 2009: On the MSC forecasters forums and the future role of the human forecaster. Bull. Amer. Meteor. Soc., 90, 619-627, doi:10.1175/2008BAMS2657.1.

Smith, M., and Coauthors, 2013: The distributed model intercomparison project-Phase 2: Experiment design and summary results of the western basin experiments. J. Hydrol., 507, 300-329, doi:10.1016/j.jhydrol.2013.08.040.

Stokstad, E., 1999: Scarcity of rain, stream gages threatens forecasts. Science, 285, 1199-1200, doi:10.1126/science.285.5431.1199.

Stuart, N. A., and Coauthors, 2006: The future of humans in an increasingly automated forecast process. Bull. Amer. Meteor. Soc., 87, 1497-1502, doi:10.1175/BAMS-87-11-1497.

_ D. M. Schultz, and G. Klein, 2007: Maintaining the role of humans in the forecast process. Bull. Amer. Meteor. Soc., 88, 1893-1898, doi:10.1175/BAMS-88-12-1893.

Thielen, J., J. Bartholmes, M.-H. Ramos, and A. de Roo, 2009: The European Flood Alert System-Part 1: Concept and development. Hydrol. Earth Syst. Sci., 13, 125-140, doi:10.5194/ hess-13-125-2009.

Thompson, S., M. Sivapalan, C. Harman, V. Srinivasan, M. Hipsey, P. Reed, A. Montanari, and G. Blöschl, 2013: Developing predictive insight into changing water systems: Use-inspired hydrologic science for the Anthropocene. Hydrol. Earth Syst. Sci., 17, 5013-5039, doi:10.5194/hess-17-5013-2013.

van Dijk, A. I. J. M., J. L. Peña-Arancibia, E. F. Wood, J. Sheffield, and H. E. Beck, 2013: Global analysis of seasonal streamflow 
predictability using an ensemble prediction system and observations from 6192 small catchments worldwide. Water Resour. Res., 49, 2729-2746, doi:10.1002/wrcr.20251.

Verkade, J. S., J. Brown, P. Reggiani, and A. H. Weerts, 2013: Post-processing ECMWF precipitation and temperature ensemble reforecasts for operational hydrologic forecasting at various spatial scales. J. Hydrol., 501, 73-91, doi:10.1016/ j.jhydrol.2013.07.039.

Viglione, A., M. Borga, P. Balabanis, and G. Blöschl, 2010: Barriers to the exchange of hydrometeorological data in Europe: Results from a survey and implications for data policy. J. Hydrol., 394, 63-77, doi:10.1016/j.jhydrol.2010.03.023.

Vörösmarty, C., and Coauthors, 2001: Global water data: A newly endangered species. Eos, Trans. Amer. Geophys. Union, 82, 54-58, doi:10.1029/01EO00031.

Wagener, T., and Coauthors, 2010: The future of hydrology: An evolving science for a changing world. Water Resour. Res., 46, W05301, doi:10.1029/2009WR008906.

Walker, G., P. Taylor, S. Cox, and P. Sheahan, 2009: Water Data Transfer Format (WDTF): Guiding principles, technical challenges and the future. Proc. 18th World IMACS Congress and MODSIM09 Int. Congress on Modelling and Simulation, Cairns, Australia, MSSANZ and IMACS, 4381-4387. [Available online at http://mssanz.org.au/modsim09/J4/walker_g. pdf.]

Wang, Q. J., D. E. Robertson, and F. H. S. Chiew, 2009: A Bayesian joint probability modeling approach for seasonal forecasting of streamflows at multiple sites. Water Resour. Res., 45, W05407, doi:10.1029/2008WR007355.
Weber, F., D. Garen, and A. Gobena, 2012: Invited commentary: Themes and issues from the workshop "Operational River Flow and Water Supply Forecasting." Can. Water Resour. J., 37, 151-161, doi:10.4296/cwrj2012-953.

Webster, P. J., and Coauthors, 2010: Extended-range probabilistic forecasts of Ganges and Brahmaputra floods in Bangladesh. Bull. Amer. Meteor. Soc., 91, 1493-1514, doi:10.1175/ 2010BAMS2911.1.

Welles, E., S. Sorooshian, G. Carter, and B. Olsen, 2007: Hydrologic verification: A call for action and collaboration. Bull. Amer. Meteor. Soc., 88, 503-511, doi:10.1175/BAMS-88-4-503.

Werner, M., M. Cranston, T. Harrison, D. Whitfield, and J. Schellekens, 2009: Recent developments in operational flood forecasting in England, Wales and Scotland. Meteor. Appl., 16, 13-22, doi:10.1002/met.124.

- J. Schellekens, P. Gijsbers, M. van Dijk, O. van den Akker, and K. Heynert, 2013: The Delft-FEWS flow forecasting system. Environ. Modell. Software, 40, 65-77, doi:10.1016/ j.envsoft.2012.07.010.

Wetterhall, F., and Coauthors, 2013: Forecasters priorities for improving probabilistic flood forecasts. Hydrol. Earth Syst. Sci. Discuss., 10, 2215-2242, doi:10.5194/hessd-10-2215-2013.

Wood, A. W., and D. P. Lettenmaier, 2008: An ensemble approach for attribution of hydrologic prediction uncertainty. Geophys. Res. Lett., 35, L14401, doi:10.1029/2008GL034648.

Zappa, M., S. Jaun, U. Germann, A. Walser, and F. Fundel, 2011: Superposition of three sources of uncertainties in operational flood forecasting chains. Atmos. Res., 100, 246-262, doi:10.1016/ j.atmosres.2010.12.005. 